\title{
Overview of recent researches in IAQ, ventilation, and energy conservation
}

\author{
Umberto Berardi ( $\square)$ \\ (Guest Editor) \\ Faculty of Engineering and Architectural Science, Ryerson University, 350 Victoria St, Toronto, ON M5B 2K3, Canada \\ (c) Tsinghua University Press and Springer-Verlag GmbH Germany, part of Springer Nature 2020
}

The International Indoor Air Quality, Ventilation and Energy Conservation (IAQVEC) conference is the premier international event in the field of indoor air quality, ventilation and energy saving. This international meeting started 30 years ago with the goal of connecting topics typically addressed separately.

IAQVEC is a premier international conference series, held once every three years since 1992, and hosted in different countries every time (in the past, it has been organized in Canada, France, China, Japan, USA, Czech Republic, R.O. Korea, lately in Italy).

The X IAQVEC 2019 focused on the theme "Healthy nearly Zero Energy Buildings" and envisaged the participation of a large number of scientists, researchers, and practitioners and the submission of papers covering a broad range of topics relevant to the goal of connecting energy saving and healthy indoor environments.

The conference was organized around five streams: ventilation and measurement techniques; IAQ and indoor environmental quality; HVAC systems; smart technologies for zero energy buildings (ZEBs); and ZEBs: design and energy modeling. The distribution of contributions among the five streams testifies the active participation of researchers active in different research areas.

X IAQVEC 2019 attracted over 500 submissions from 77 countries around the world, and had over 300 oral presentations. Among these papers, the International Scientific Committee, chaired by Prof. Francis Allard, select the best papers whose authors were invited to extend their study and submit an extended paper to Building Simulation: An International Journal.

The partenership between the conference and this journal emerged naturally, as the role of building simulation is of the foremost importance to meet the requirements of healthy nearly zero energy buildings and to evaluate high performance E-mail: uberardi@ryerson.ca of both IAQ and energy aspects in buildings. Among the topics of the IAQVEC 2019 Conference, the topical issue on "IAQ and Indoor Pollution Modelling" addressed the following streams: air quality modelling; simulation of heating, ventilation and air conditioning (HVAC); pollution and contaminants modeling; and healthy nearly zero energy buildings (ZEB).

This special issue includes papers of extremely high value and interest, as briefly reported below.

The distribution of contaminants and pollutions in indoor environments is discussed using numerical models by Agirman et al. (2020) in the paper "Effect of air exhaust location on surgical site particle distribution in an operating room", and by Zhang et al. (2020) in their paper "On the capture of polar indoor air pollutants at sub-ppm level-A molecular simulation study". Looking at the effects of moisture-related issues, Lopez-Arce et al. (2020) present a comprehensive review on "Building moisture diagnosis: Processing, assessing and representation of environmental data for root cause analysis of mould growth".

Campaigns of IAQ/IEQ measurements are presented by Qiu et al. (2020) in the paper "Investigation of indoor air quality in six office buildings in Chengdu, China based on field measurements" of both indoor particulate matter $\left(\mathrm{PM}_{2.5}\right)$ and carbon dioxide $\left(\mathrm{CO}_{2}\right)$, and Gupta and Howard (2020) in "Comparative evaluation of measured and perceived indoor environmental conditions in naturally and mechanically ventilated office environments", Elnaklah et al. (2020) in "Indoor environment quality and work performance in 'green' office buildings in the Middle East", and Mutlu (2020) in "Numerical investigation of indoor air quality in a floor heated room with different air change rates". Particularly interesting is the contribution by $\mathrm{Na}$ et al. (2020) titled "Metabolic rate estimation method using image deep learning"; as the title suggests the study metabolic equivalent 
of task was measured for eight typical indoor tasks based on the ASHRAE Standard 55.

Beyond researches about the awareness of IAQ issues, the special issue and the conference program (and related expo) were enriched by contributions on technical solutions for improving IAQ issues. For example, in this issue, the readers are invited to enjoy the study by Luo et al. (2020) who present "An improved numerical model of a UV-PCO reactor for air purification applications"; the study presents Ultraviolet photocatalytic oxidation (UV-PCO) as a promising gaseous volatile organic compounds (VOCs) elimination method, of which the PCO kinetics are closely related to the radiation and airflow (contaminants) fields. On the same stream, Xu et al. (2020) presented "Bio-inspired patterned surface for submicron particle deposition in a fully developed turbulent duct"; in this study different forms of surface ribs inspired by nature were designed and parametric studies were performed to enhance deposition efficiency. The flow field around patterned surfaces was simulated in a two-dimensional channel flow by using the Reynolds stress model, while the particle trajectory was solved by using Lagrangian particle tracking.

Finally, innovative HVAC systems for thermal comfort and energy saving are presented by Berardi et al. (2020) in "Enhancing the cooling potential of a solar-assisted desiccant cooling system by ground source free cooling" while smart energy-saving strategies are presented by Qian et al. (2020) in "Power consumption and energy efficiency of VRF system based on large scale monitoring virtual sensors"; this study proposes a virtual sensor modeling method to determine the actual energy efficiency and electricity consumption of 344 variable refrigerant flow (VRF) systems in residential buildings. Statistical and clustering analyses are conducted to determine the energy efficiency and electricity consumption to obtain distributions and typical operation load patterns of VRF systems in residential buildings in China.

It is my pleasure to thank all peer reviewers for their fair and rigorous reviews and for their suggestive comments. I also would like to thank all authors for their tremendous effort. Organizing such a large event is challenging and rewarding, and I hope this special issue can testify the prolific work that the organizing and scientific committees have done to attract and coordinate such a diverse community.
To conclude, on behalf of the IAQVEC organizing committee, I would like to thank Prof. Xudong Yang and the editorial staff of Building Simulation: An International Journal for the contribution made to the dissemination of the results of the X IAQVE 2019 conference.

\section{References}

Agirman A, Cetin YE, Avci M, Aydin O (2020). Effect of air exhaust location on surgical site particle distribution in an operating room. Building Simulation, 13: 979-988.

Berardi U, Heidarinejad G, Rayegan S, Pasdarshahri H (2020). Enhancing the cooling potential of a solar-assisted desiccant cooling system by ground source free cooling. Building Simulation, 13: 1125-1144.

Elnaklah R, Fosas D, Natarajan S (2020). Indoor environment quality and work performance in "green" office buildings in the Middle East. Building Simulation, 13: 1043-1062.

Gupta R, Howard A (2020). Comparative evaluation of measured and perceived indoor environmental conditions in naturally and mechanically ventilated office environments. Building Simulation, 13: 1021-1042.

Lopez-Arce P, Altamirano-Medina H, Berry J, Rovas D, Sarce F, et al. (2020). Building moisture diagnosis: Processing, assessing and representation of environmental data for root cause analysis of mould growth. Building Simulation, : 13: 999-1008.

Luo H, Zhang G, Hashisho Z, Zhong L (2020). An improved numerical model of a UV-PCO reactor for air purification applications. Building Simulation, 13: 1095-1110.

Mutlu M (2020). Numerical investigation of indoor air quality in a floor heated room with different air change rates. Building Simulation, 13: 1063-1075.

$\mathrm{Na} \mathrm{H}$, Choi H, Kim T (2020). Metabolic rate estimation method using image deep learning. Building Simulation, 13: 1077-1093.

Qian M, Yan D, Liu H, Berardi U, Liu Y (2020). Power consumption and energy efficiency of VRF system based on large scale monitoring virtual sensors. Building Simulation, 13: 1145-1156.

Qiu Y, Wang Y, Tang Y (2020). Investigation of indoor air quality in six office buildings in Chengdu, China based on field measurements. Building Simulation, 13: 1009-1020.

Xu H, Fu SC, Chan KC, Qiu H, Chao CYH (2020). Bio-inspired patterned surface for submicron particle deposition in a fully developed turbulent duct. Building Simulation, 13: 1111-1123.

Zhang D, Liu J, Liu L (2020). On the capture of polar indoor air pollutants at sub-ppm level-A molecular simulation study. Building Simulation, 13: 989-997. 